\title{
In memoriam Mario Savoiardo, M.D.
}

\author{
Massimo Gallucci • Maria Consuelo Valentini • \\ Ludovico D'Incerti - Andrea Rossi - On behalf of the \\ Italian Association of Neuroradiology (AINR)
}

Published online: 29 March 2014

(C) Springer-Verlag Berlin Heidelberg 2014

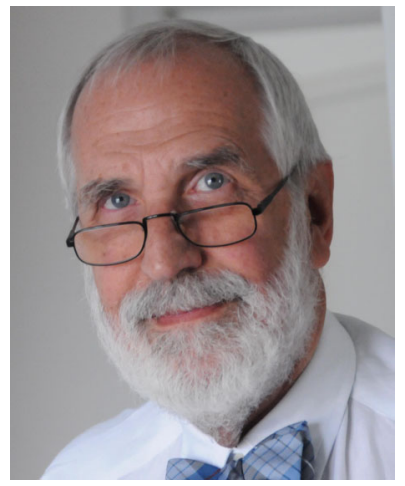

Mario Savoiardo, former Head of Neuroradiology at "Carlo Besta" National Neurological Institute in Milan and a worldclass, influential Italian neuroradiologist, passed away on January 30, 2014 after a long battle with illness. He undertook his ordeal with dignity and silence while continuing to profess his enthusiasm and dedication to our discipline until his final days. Mario passed with discretion as was in his character to do, and peacefully as he deserved.

\footnotetext{
M. Gallucci $(\square)$

University Hospital San Salvatore, Neuroradiology Unit, L'Aquila, Italy

e-mail: massimo.gallucci@cc.univaq.it

M. C. Valentini

Hospital "Le Molinette", Neuroradiology Unit, Torino, Italy

L. D'Incerti

Neurological Institute “C. Besta”, Neuroradiology Unit, Milano, Italy

\author{
A. Rossi \\ Pediatric Hospital “G.Gaslini”, Neuroradiology Unit, Genova, Italy
}

Mario was born on July 5, 1939 in Corsico, near Milan, Italy, where he graduated in medicine in 1965 and then specialized in neurology. After marrying Maria Riccarda, he moved to the USA where he spent 3 years as a fellow at Boston University. There, he became interested in neuroradiology thanks to his encounter with Marjorie LeMay, with whom he remained bound by deep respect and affection. His beloved twin daughters, Cristina and Silvia, were born during this time in the USA. He returned to Italy at the end of 1971 to devote himself to neuroradiology. Thus, he began his career at Besta Institute in Milan, under the guidance of Professor Guido Lombardi. He then specialized in diagnostic radiology at the University of Padua in 1973 and returned to the USA for a postdoc at the Pediatric Neuroradiology Unit of the Hospital for Sick Children in Toronto with Derek Harwood-Nash and, then again in 1987, at the Children's Hospital of Philadelphia with Robert A. Zimmerman. Mario spent his whole career at Besta Institute, retiring in March 2005, but actually continuing as a consultant until the very end of his life.

Mario Savoiardo's contributions to the field of neurosciences are enormous. Over the years, he published hundreds of scientific papers, many of which became cornerstones of neuroradiology, including breakthrough works on angiography of posterior fossa lesions, vascular territories of the cerebellum and brain stem, and diagnosis of optic pathway gliomas and CSF hypotension as well as his numerous studies on neurodegenerative and metabolic disorders. Mario was also very active in the Italian Association of Neuroradiology, sitting as a member of the executive committee for many years and eventually being awarded a honorary membership. He was inspirational for more than a generation of neuroradiologists; although internationally renowned, he remained down-to-earth, easily approachable, and always willing to solve complex cases with his expertise, insight, and constant availability and generosity.

Among his various qualities, he was perhaps better defined by his passion. With passion, in fact, he faced every aspect of 
his daily work. Passion fueled his refined reasoning which, supported by his famous elephant's memory, made him recognized as one of the most knowledgeable diagnostic neuroradiologists around. These qualities were cleverly contained in a discreet, unassuming attitude - never arrogant, always available. Thus, he was loved and respected by many colleagues around the world. Passion also resulted in his intolerance to approximation and compromise. His "modus vivendi" was to give and demand the most, first from himself and then others, with rigor and no discounts.

Perhaps unknown to many, Mario also displayed a vivid artistic talent, taking on drawing, photography, and painting. During conventions, it was not uncommon to catch him taking his pencil and sketching, with fast hands, the face or profile of the speaker or someone in the audience. Painting always accompanied him in a lasting quest for beauty; lately, he had started tasting the sensitivity and vibrations of print engraving. He was also very effective at writing, and in his book Piccoli ricordi (Small memories), he recounted with humor and delicacy several episodes of his life as a doctor, his experiences in dealing with patients, and many events with friends.

Despite his several compelling professional commitments, Mario remained firmly present as a family man, husband, father, and grandfather. He taught us all the importance of defending our actions with firmness, authority, and even elegance; he made us aware of how crucial it is to inspire the young to analyze and compare, dispensing them our encouragement sparingly, but without avarice. Mario leaves to neuroradiology his profound cultural and moral heritage. He will be dearly missed, and his memory will be cherished by all who had the privilege of knowing him. Our warmest thoughts are with his wife, daughters, and grandchildren. 